\title{
Implementation concepts for a bridging protocol for the high data rate slow-fading Free-Space Optical Channel
}

\author{
Bernhard Epple ${ }^{*}$, Clara Serrano Solsona ${ }^{a}$ \\ ${ }^{a}$ German Aerospace Center (DLR), Institute of Communications and Navigation, 82234 Wessling, \\ Germany
}

\begin{abstract}
This paper addresses various aspects for designing and implementing a bridging protocol for reliable data transfer between two local area networks over the high data rate slow-fading free-space optical channel. First the service requirements of widely spread applications of today's life like voice communication, video streaming or file transfer are given and the resulting constrains for data transfer protocols are compiled. Then, based on the physical characteristics of different communication scenarios and the compiled results, the feasibility of these services on optical free-space links is studied. Finally different protocol design aspects are discussed and an implementation concept for bridging data of different services over free-space optical links is presented.
\end{abstract}

Keywords: Free-space optical communication, data transfer, bridge, protocol design, service requirements

\section{INTRODUCTION}

Work presented in this paper relates to the European Union funded project MINERVAA ${ }^{1}$ which deals with the development and in-flight validation of an airborne FSO communication terminal.

With the advances in communication technology and the growing demand by end-users to use new communication technologies as part of their daily life, new communication devices are emerging on the market. This development leads to heterogeneous, highly-dynamic networks with a growing demand of bandwidth. To overcome the bandwidth limitations of current technologies new communication technologies are developed. One of these technologies that are currently worked on is free-space optical communication (FSO). While these new technologies are developed and integrated into existing networks, the technical complexity of these networks is raised. To reduce the complexity of networks and also to reduce their operational costs, more and more networks are transferred to all-IP networks. By this change of infrastructure the infrastructure on top of the data link layer of the OSI Reference Model (layer 2) is unified. In this paper established Quality of Service (QoS) categories for network services above layer 2 will be listed, combined with a short summary of the special channel characteristics for FSO. This listing is followed by an analysis on how FSO can be utilized to transport common end-user multimedia data between two local area networks (LAN) as illustrated in Figure 1. For new communication infrastructure it is very important that the end-users have the same quality of communication experience as if they were using technologies that they are already used to. To guarantee a certain QoS for transported data over FSO links, additional error correcting and error protecting protocols are needed. For fulfilling this task, existing protocols can be adapted to the special FSO channel characteristics and they can also be combined to form new protocols. Aspects for implementing such protocols will be discussed in the final part of this paper.

\footnotetext{
*Bernhard.Epple@dlr.de; phone +49 (0) 8153 2816; fax +49 (0) 8153 2844; www.dlr.de/kn/

Copyright 2008 Society of Photo-Optical Instrumentation Engineers. This paper was published in Proceedings of the SPIE Vol. 6877 and is made available as an electronic reprint with permission of SPIE. One print or electronic copy may be made for personal use only. Systematic or multiple reproduction, distribution to multiple locations via electronic or other means, duplication of any material in this paper for a fee or for commercial purposes, or modification of the content of the paper are prohibited.
} 


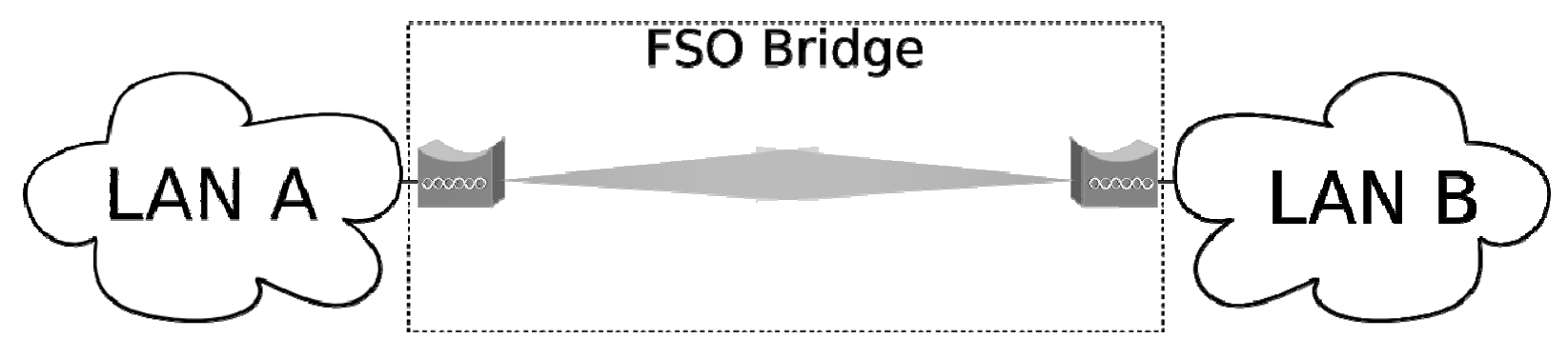

Fig. 1: Illustration of the FSO Bridge concept. LAN A and LAN B are connected together vi the FSO Bridge. This connection is transparent to all applications using IP technology.

\section{TYPICAL SERVICE REQUIREMENTS AND QUALITY OF SERVICE CATEGORIES}

Communication service providers offer a wide variety of different communication services for the end-user. Examples are voice over IP (VoIP), video conferencing, email, web surfing, file downloads, location based services, video and audio streaming and others. All these services have special requirements on the main parameters data rate, delay (latency), delay jitter and data loss ratio. Because the different services have different requirements it would not be efficient to treat all service traffic on the transport layer in the same way. Therefore the available services have been grouped into QoS classes to give specification which demands these services have on the transporting layers. The connections that should transfer data belonging to a special QoS class have to meet the given requirements; otherwise the offered service can not be used by end-users in a satisfying way. For grouping of the existing services and to make the QoS measureable and implementable the 3rd Generation Partnership Project (3GPP), the Institute of Electrical and Electronics Engineers (IEEE), the Internet Engineering Task Force (IETF) and the International Telecommunication Union (ITU) have each worked out their own QoS classes, $3,4,5,6$. The IEEE and IETF focus more on ways for implementing QoS without giving values for the QoS requirements while 3GPP and ITU give precise end-to-end target values for enabling different services.

Table 1: QoS classification and target values proposed by 3 GPP and ITU. In this table the values give by these institutions are combined to a common value. For services that have a zero loss requirement, the delay can be understood as a limit for $95 \%$ of transmitted data.

\begin{tabular}{|l|l|l|l|l|}
\hline \multicolumn{1}{|c|}{ Institution } & $\begin{array}{l}\text { Classification Name } \\
\text { 3GPP - ITU }\end{array}$ & Delay & Jitter & $\begin{array}{l}\text { Loss } \\
\text { Frame Erasure Rate } \\
\text { (FER) }\end{array}$ \\
\hline Remote Control & $\begin{array}{l}\text { Conversational - } \\
\text { Error Intolerant / } \\
\text { Interactive }\end{array}$ & $\begin{array}{l}<75 \mathrm{~ms} \text { (preferred) } \\
200-250 \mathrm{~ms} \text { (limit) }\end{array}$ & N.A. & Zero \\
\hline Online Games & $\begin{array}{l}\text { Conversational - } \\
\text { Error Intolerant / } \\
\text { Interactive }\end{array}$ & $\begin{array}{l}<75 \mathrm{~ms} \\
<200-250 \mathrm{~ms}\end{array}$ & $<3 \%$ FER (preferred) \\
\hline VoIP & $\begin{array}{l}\text { Conversational - } \\
\text { Error Tolerant / } \\
\text { Interactive }\end{array}$ & $\begin{array}{l}<<150 \mathrm{~ms} \text { (preferred) } \\
<<400 \mathrm{~ms} \text { (limit) }\end{array}$ & $<1 \mathrm{~ms}$ & $<3 \%$ FER (limit) \\
\hline Video conference & $\begin{array}{l}\text { Conversational - } \\
\text { Error Tolerant / } \\
\text { Interactive }\end{array}$ & $\begin{array}{l}<150 \mathrm{~ms} \text { (preferred) } \\
<400 \mathrm{~ms} \text { (limit) } \\
\text { Lip-synch: }<100 \mathrm{msec}\end{array}$ & $<1 \%$ FER \\
\hline
\end{tabular}




\begin{tabular}{|c|c|c|c|c|}
\hline Web browsing & \begin{tabular}{|l} 
Interactive - \\
Error Intolerant / \\
Responsive
\end{tabular} & $\mid \begin{array}{l}<2 \text { s / page (preferred) } \\
<4 \text { s / page }(\text { acceptable) }\end{array}$ & N.A. & Zero \\
\hline Audio/Video Messaging & $\begin{array}{l}\text { Interactive - } \\
\text { Error Tolerant / } \\
\text { Responsive }\end{array}$ & $\begin{array}{l}<1 \text { s for playback } \\
<2 \text { s for record }\end{array}$ & $<1 \mathrm{~ms}$ & $<3 \%$ FER \\
\hline $\begin{array}{l}\text { Text Messaging, } \\
\text { Downloads (FTP) }\end{array}$ & $\begin{array}{l}\text { Streaming - } \\
\text { Error Intolerant / Timely }\end{array}$ & $\begin{array}{l}<15 \text { s (preferred) } \\
<60 \text { s (acceptable) }\end{array}$ & N.A. & Zero \\
\hline Email & $\begin{array}{l}\text { Streaming - } \\
\text { Error Intolerant / Timely }\end{array}$ & $\begin{array}{l}<2 \text { s (preferred) } \\
<4 \text { s (acceptable) } \\
<10 \text { s (limit) }\end{array}$ & N.A. & Zero \\
\hline Video/Audio streaming & $\begin{array}{l}\text { Streaming - } \\
\text { Error Tolerant / Timely }\end{array}$ & $\begin{array}{l}<2 \text { s (preferred) } \\
<4 \text { s (acceptable) } \\
<10 \text { s (limit) }\end{array}$ & $<<1 \mathrm{~ms}$ & $\begin{array}{l}<1 \% \text { FER (Audio) } \\
<2 \% \text { FER (Video) }\end{array}$ \\
\hline $\begin{array}{l}\text { Background (Usenet, } \\
\text { Filesharing) }\end{array}$ & $\begin{array}{l}\text { Background - } \\
\text { Error Intolerant / Non- } \\
\text { Critical }\end{array}$ & $>10 \mathrm{~s}$ & N.A. & Zero \\
\hline Fax & $\begin{array}{l}\text { Background - } \\
\text { Error Tolerant / Non- } \\
\text { Critical }\end{array}$ & $<30$ s / page & N.A. & $<10^{-6}$ BER \\
\hline
\end{tabular}

\section{FREE-SPACE OPTICAL CHANNEL CHARACTERISTICS}

The most significant characteristic of the FSO channel is its time-varying nature. Received power fluctuation is caused by index of refraction turbulence and temporary transceiver misalignment. These fluctuations, called scintillation, cause fades and surges in the received signal, which can have durations ranging from less than $1 \mathrm{~ms}$ to several $100 \mathrm{~ms}$ and a scintillation loss of up to $20 \mathrm{~dB}$ or even more in some cases. The fade duration is mainly influenced by the wind speed and the relative velocity between the communication partners, while the scintillation loss mainly depends on the link distance. On short distances, for example between two buildings in a city, it is possible to completely eliminate fades by a power margin in the link budget; on longer distances this is not possible due to eye safety regulations and by available technology. For longer link distances other ways to overcome signal loss due to fades have to be found. 
Table 2: Characteristic values for FSO links in selected communication scenarios gained from measurements and simulations done by DLR. The packet loss ratio is calculated for the maximum Ethernet packet size of 1518 byte sent over an AWGN channel. It has to be noted that the given BER values are long term measurements. Due to fading and surges the BER will vary around this value. The range of this variation is given in the last column; the given values are based on experience and only suitable to give a rough number of the strength of the variations.

\begin{tabular}{|c|c|c|c|c|c|c|}
\hline$\#$ & Scenario & $\begin{array}{l}\text { Link Distance } \\
(\mathbf{k m})\end{array}$ & $\begin{array}{l}\text { Propagation } \\
\text { Delay (ms) }\end{array}$ & $\begin{array}{l}\text { Channel } \\
\text { Coherence Time } \\
\text { (Fade Duration) }\end{array}$ & $\begin{array}{lr}\text { Long } & \text { Term Bit } \\
\text { Error } & \text { Ratio } \\
\text { (BER) } & \text { / Packet } \\
\text { Loss } & \text { Ratio } \\
\text { (PLR) } & \\
\end{array}$ & $\begin{array}{l}\text { Short Term BER / } \\
\text { PLR range }\end{array}$ \\
\hline 1 & $\begin{array}{l}\text { High Data-Rate } \\
\text { LEO Downlink }\end{array}$ & $400-2500$ & $1.3-8.3$ & $0.1 \mathrm{~ms}$ & $10^{-4} / 70.3 \%$ & $\begin{array}{l}0.5-10^{-8} / \\
100 \%-0.012 \%\end{array}$ \\
\hline 2 & UAV - Ground & 60 & 0.2 & $0.1 \mathrm{~ms}$ & $10^{-6} / 1.2 \%$ & $\begin{array}{l}10^{-3-} 10^{-10} / \\
100 \%-<0.0001 \%\end{array}$ \\
\hline 3 & $\begin{array}{ll}\text { Aircraft } & - \\
\text { Aircraft } & \end{array}$ & $20-400$ & $0.06-1.3$ & $1-3 \mathrm{~ms}$ & $10^{-6} / 1.2 \%$ & $\begin{array}{l}10^{-4}-10^{-8} / \\
70.3 \%-0.012 \%\end{array}$ \\
\hline 4 & $\begin{array}{l}\text { Maritime } \\
\text { Mobile }\end{array}$ & $1-25$ & $\begin{array}{ll}0.003 & - \\
0.083 & \end{array}$ & $10-100 \mathrm{~ms}$ & $10^{-3} / 100 \%$ & $\begin{array}{l}0.5-10^{-7} / \\
100 \%-<0.12 \%\end{array}$ \\
\hline 5 & $\begin{array}{l}\text { Military Land- } \\
\text { Mobile }\end{array}$ & $1-25$ & $\begin{array}{l}0.003 \\
0.083\end{array}$ & $10-100 \mathrm{~ms}$ & $10^{-3} / 100 \%$ & $\begin{array}{l}0.5^{-} 10^{-7} / \\
100 \%-<0.12 \%\end{array}$ \\
\hline 6 & GEO Downlink & 40000 & 133 & $1 \mathrm{~ms}$ & $10^{-7} / 0.12 \%$ & $\begin{array}{l}10^{-5}-10^{-7} / \\
11,4 \%-<0.12 \%\end{array}$ \\
\hline 7 & $\begin{array}{l}\text { HAP }- \text { HAP } \\
\text { (High Altitude } \\
\text { Platforms) }\end{array}$ & 800 & 2.6 & $10 \mathrm{~ms}$ & $<10^{-9} /<0.001 \%$ & $\begin{array}{l}10^{-7}-10^{-10} / \\
0.12 \%-<0.0001 \%\end{array}$ \\
\hline
\end{tabular}

The high data-rate LEO downlink, maritime mobile and the military land-mobile scenario have to deal with the problem of temporarily blockings of the line of sight by clouds, trees, poles, and others. These complete blockings cause very large long-term BER values because no data transmission is possible and this no-data outage is interpreted by common BER measurement hardware as bit errors. If no blocking occurs these links offer a good link quality. For implementing services in these three scenarios this special characteristic has to be kept in mind. If strongly asymmetric services like bulk data transfer shall be implemented in these scenarios it would be advisable to implement packet layer forward error correction which introduces long coding delays into the transmission, but has the power to correct the errors introduced into the data stream by the complete blockings of the line of sight. Realtime services will always experience interruptions (data loss) in these scenarios.

\section{PROTOCOL IMPLEMENTATION CONSIDERATIONS}

In ${ }^{7}$ it is show that it is possible to reduce the BER from worst case $10^{-3}$ to something smaller than $10^{-7}$ by using Forward Error Correction (FEC) on the physical layer. In this range the coding can be implemented quite efficient so that nearly no coding overhead and coding delay occurs. If the channel gets worse than $10^{-3}$ for several milliseconds, FEC would have to introduce so much redundancy data into the data stream that long coding delays would become noticeable and channel throughput would be heavily reduced. In that situation the channel can be assumed as blocked. The occurrence of such very deep fades should be in general very rare and the duration of such blockings should be within the channel coherence time. For further improving the channel quality, error correction schemes on higher layers are needed. Because of the ongoing trend towards all-IP networks it is suggested to implement the error correction scheme below the IP-layer which means to implement it on layer 2 of the OSI Reference Model. In the following it is assumed that the implemented bridge operates on layer 2 the terms packet and frame are used interchangeably and refer always to the Ethernet frames present on layer 2. A common error correcting technique for bidirectional communication links is 
Automatic Repeat reQuest (ARQ). The successful application of ARQ in the FSO channel has been shown in ${ }^{8}$. ARQ is based on the retransmission of corrupted packets, where different retransmission strategies are known. For the relatively long distances that are present in the selected scenarios it can be said that Selective Repeat ARQ or Hybrid ARQ are the most suitable ${ }^{8}$. In the following some implementation aspects for ARQ protocols are discussed in more detail. All recommendations and considerations are made for a small system consisting of two local area networks with negligible delays and a FSO link as bridge between these two networks (Figure 1). For example in the aircraft to aircraft scenario each of the networks is located in a separate plane and the FSO link bridges the traffic between these two planes.

\subsection{Transfer delay and Number of Retransmissions}

In communication systems the transfer delay of the data flow is mainly determined by the propagation delay of the transmitting signal. In presence of errors, the retransmissions in ARQ introduce additional delay in the order of twice the propagation delay plus the time needed by the protocol stack for processing the packets. In case of a bad channel state where many retransmissions are needed for the successful delivery of a data packet this can heavily increase the transfer delay. The number of needed retransmissions for each packet is not a constant value; it depends on the state of the channel and can range from 0 retransmissions in a good state to infinite retransmissions in a very bad channel state. Logically the varying number of retransmissions per packet leads to jitter of the transfer delay. For QoS the delay and the delay variation (jitter) are important values. As shown in Table 1 some services like VoIP or video conferences are sensitive to both of them. The problems caused by the retransmission jitter can be reduced by buffering at the receiver which is described in the next section. For receiving a deterministic transmission delay the only solution is to limit the number of retransmissions which leads to a residual packet loss as illustrated in Figure 1.

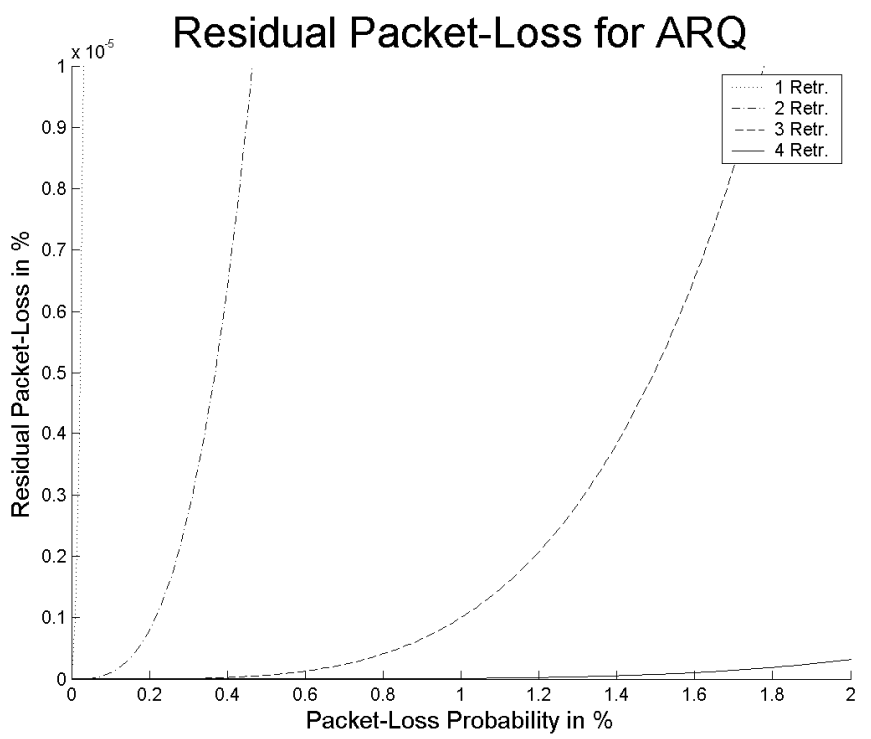

Fig. 2: Illustration of the residual packet-loss for different numbers of retransmission (1-4). It can be seen that for a packetloss probability of $2 \%$ and the use of 4 retransmissions the residual packet-loss is close to $0\left(<10^{-6} \%\right.$. The given plot is valid for transmission over an AWGN channel.

With the underlying FEC a packet loss of not larger than $2 \%$ can be expected in the selected scenarios. From Figure 1 it can be seen that for four retransmissions the residual packet loss stays very close to zero, so a limit of four retransmissions seems to be a good compromise between delay and residual error. One important thing is to mention here. If during a strong fade the BER becomes larger than $10^{-3}$ the underlying FEC can no longer correct errors and nearly all transmitted frames will get lost. For long fade durations like they are present in the maritime mobile scenario it would be possible that the suggested four retransmissions are all done during this deep fade and therefore get lost. In such scenarios it is advisable to either raise the number of allowed retransmissions or to introduce a delay between retransmissions in the order of the mean expected fade duration. For scenarios with shorter fade durations this problem does not apply because the processing time needed by the protocol stack for one retransmission $(\sim 10 \mathrm{~ms})$ should be longer than the typical fade duration. Following connection between the packet-loss probability of the channel, the 
maximum number of retransmission $N_{\max }$ and the throughput efficiency can be given as base for considerations. If the packet-loss propability $p$ of the channel rises, the throughput efficiency of the protocol degenerates and the residual error rises if the number of retransmissions is limited.

\section{$\uparrow$ Packet-Loss Probability $(p)\left\{\begin{array}{l}\downarrow \text { Throughput Efficiency } \\ \uparrow \text { Residual Error }\end{array}\right.$}

If $\mathrm{N}_{\max }$ is raised this has the following effect. The residual error probability is lowered due to the additional retransmissions. The transmission delay rises because of the additional retransmissions and the needed buffer size at the receiver also goes up. The additional retransmissions reduce the throughput efficiency of the protocol slightly, but this should not be a real problem.

$$
\uparrow N_{\max }\left\{\begin{array}{l}
\downarrow \text { Residual Error Probability } \\
\uparrow \text { Delay (QoS) } \\
\uparrow \text { Buffer Size (Buffering Problems) } \\
\downarrow \text { Throughput Efficiency }
\end{array}\right.
$$

\subsection{Service feasibility Matrix}

Using the values from Table 1 and Table 2 and the delay considerations from the previous section it is possible to evaluate the feasibility of providing the selected services in the communication scenarios. This is done in Table 3 . For evaluating services as feasible, it has been assumed that the quality of the physical layer is improved by the use of FEC and following three rules have been used. First, a service is feasible in the scenario if the propagation time of the signal is less than the maximum allowed delay. Second, if the service has a zero loss constraint at least four retransmissions have to be possible within the maximum allowed delay. The delay for services requiring zero loss is generally given as a value for $95 \%$ of the transmitted data. This requirement should be overfulfilled by applying the second rule. The duration needed for one retransmission has been calculated by using the round trip time plus $10 \mathrm{~ms}$ for the processing of the retransmission request in the protocol stack. Third, if the service allows for more than $1 \%$ loss no ARQ is needed at all

Table 3: Feasibility matrix for the different services in the selected scenarios. The values give the number of maximum possible retransmissions within the delay constraints given by ITU and 3GPP. If a service does not need any additional error correction than the FEC on the physical layer it is marked by the abbreviation nAn for "no ARQ needed", if a service can not be realized in a certain scenario it is marked by X. The given values assume the FSO link as bridge between two networks with no significant additional delay for the communication. If additional hops or other sources for delay are present, the values have to be recalculated taking the additional delay into account.

\begin{tabular}{|c|c|c|c|c|c|c|c|}
\hline $\begin{array}{l}\text { Scenario } \\
\text { Application }\end{array}$ & $\begin{array}{l}\text { High Data- } \\
\text { Rate LEO } \\
\text { Downlink }\end{array}$ & $\begin{array}{l}\text { UAV - } \\
\text { Ground }\end{array}$ & $\begin{array}{l}\text { Aircraft - } \\
\text { Aircraft }\end{array}$ & $\begin{array}{l}\text { Maritime } \\
\text { mobile }\end{array}$ & $\begin{array}{l}\text { Military } \\
\text { land-mobile }\end{array}$ & $\begin{array}{l}\text { GEO } \\
\text { downlink }\end{array}$ & HAP - HAP \\
\hline Remote Control & $\begin{array}{l}X \text { (preferred) } \\
9 \text { (limit) }\end{array}$ & $\begin{array}{l}7 \text { (preferred) } \\
24 \text { (limit) }\end{array}$ & $\begin{array}{l}5 \text { (preferred) } \\
19 \text { (limit) }\end{array}$ & $\begin{array}{l}7 \text { (preferred) } \\
24 \text { (limit) }\end{array}$ & $\begin{array}{l}7 \text { (preferred) } \\
24 \text { (limit) }\end{array}$ & $\begin{array}{l}X \text { (preferred) } \\
X \text { (limit) }\end{array}$ & $\begin{array}{l}4 \text { (preferred) } \\
16 \text { (limit) }\end{array}$ \\
\hline $\begin{array}{l}\text { Online Games } \\
\text { (nAn) }\end{array}$ & $\begin{array}{l}2 \text { (preferred) } \\
9 \text { (limit) }\end{array}$ & $\begin{array}{l}7 \text { (preferred) } \\
24 \text { (limit) }\end{array}$ & $\begin{array}{l}5 \text { (preferred) } \\
19 \text { (limit) }\end{array}$ & $\begin{array}{l}7 \text { (preferred) } \\
24 \text { (limit) }\end{array}$ & $\begin{array}{l}7 \text { (preferred) } \\
24 \text { (limit) }\end{array}$ & $\begin{array}{l}X \text { (preferred) } \\
0 \text { (limit) }\end{array}$ & $\begin{array}{l}4 \text { (preferred) } \\
16 \text { (limit) }\end{array}$ \\
\hline $\begin{array}{l}\text { VoIP } \\
(\mathrm{nAn})\end{array}$ & $\begin{array}{l}3 \text { (preferred) } \\
15 \text { (limit) }\end{array}$ & $\begin{array}{l}9 \text { (preferred) } \\
38 \text { (limit) }\end{array}$ & $\begin{array}{l}7 \text { (preferred) } \\
31 \text { (limit) }\end{array}$ & $\begin{array}{l}9 \text { (preferred) } \\
39 \text { (limit) }\end{array}$ & $\begin{array}{l}9 \text { (preferred) } \\
39 \text { (limit) }\end{array}$ & $\begin{array}{l}0 \text { (preferred) } \\
0 \text { (limit) }\end{array}$ & $\begin{array}{l}6 \text { (preferred) } \\
26 \text { (limit) }\end{array}$ \\
\hline $\begin{array}{l}\text { Video conference } \\
(\mathrm{nAn})\end{array}$ & $\begin{array}{l}3 \text { (preferred) } \\
15 \text { (limit) }\end{array}$ & $\begin{array}{l}9 \text { (preferred) } \\
38 \text { (limit) }\end{array}$ & $\begin{array}{l}7 \text { (preferred) } \\
31 \text { (limit) }\end{array}$ & $\begin{array}{l}9 \text { (preferred) } \\
39 \text { (limit) }\end{array}$ & $\begin{array}{l}9 \text { (preferred) } \\
39 \text { (limit) }\end{array}$ & $\begin{array}{l}0 \text { (preferred) } \\
0 \text { (limit) }\end{array}$ & $\begin{array}{l}6 \text { (preferred) } \\
26 \text { (limit) }\end{array}$ \\
\hline
\end{tabular}




\begin{tabular}{|l|l|l|l|l|l|l|l|}
\cline { 2 - 8 } Web browsing & $75-150$ & $192-384$ & $158-317$ & $196-393$ & $196-393$ & $6-13$ & $131-263$ \\
\hline $\begin{array}{l}\text { Audio/Video } \\
\text { Messaging } \\
\text { (nAn) }\end{array}$ & $37-75$ & $96-192$ & $79-158$ & $98-196$ & $98-196$ & $3-6$ & $65-131$ \\
\hline $\begin{array}{l}\text { Text Messaging, } \\
\text { Downloads (FTP) }\end{array}$ & 375 & 961 & 793 & 983 & 983 & 34 & 657 \\
\hline $\begin{array}{l}\text { Video/Audio } \\
\text { streaming }\end{array}$ & 375 & 961 & 793 & 983 & 983 & 34 & 657 \\
\hline Email & 375 & 961 & 793 & 983 & 983 & 34 & 657 \\
\hline $\begin{array}{l}\text { Background } \\
\text { (Usenet, } \\
\text { Filesharing) }\end{array}$ & 375 & 961 & 793 & 983 & 983 & 34 & 657 \\
\hline $\begin{array}{l}\text { Fax } \\
\text { (nAn) }\end{array}$ & 1127 & 2884 & 2380 & 2951 & 2951 & 104 & 1973 \\
\hline
\end{tabular}

\subsection{Buffers in ARQ}

The implementation of ARQ protocols requires the implementation of some buffers. At the sender one buffer is needed for storing the sent packets until they are acknowledged by the receiver and then can be deleted. The size of this buffer is important for the performance of the system. If the buffer size is set too small so the buffer gets filled to its limit while no packet got acknowledged, the sender can not send new packets and therefore the throughput is limited. The minimum needed buffer size is the product of round trip time RTT and data rate $d$. Where RTT is made up from twice the propagation delay of the signal plus the processing time needed by the protocol stack.

$$
\text { BufferSize }_{T x}=R T T \times d
$$

Assuming a $1.5 \mathrm{Gbit} / \mathrm{s}$ optical link the minimum sender buffer size in the GEO relay scenario would be around 50 Megabyte. For an aircraft to aircraft link it would only be 0.5 Megabyte.

The buffers at the receiver side are more difficult. If jitter sensitive data is transmitted a so called play-out buffer is needed separately for each data flow. These play-out buffers are used to store the data for a while at the receiver before forwarding it to the actual destination at a constant rate. For setting the initial hold up of the communication flow several ways exist. It can either be set to a fixed value according to the delay values allowed by the service or it can be calculated from measurements made during previous packet transmissions. For optimum play-out the first transmitted packet should be held back at the receiver until the mean expected frame delay has passed. If the play-out buffer size is limited, the initial delay has to match the play-out duration of half of the data stored in the buffer, if the play-out duration is less than the mean delay experienced by the frames. For the play-out of the packets after the initial hold up the sender should add a time stamp to the packets. This time stamp can then be used by the receiver to calculate the original delay between the packets for the play-out, thus eliminating the jitter introduced by the ARQ protocol. It is hard to determine the number of needed play-out buffers as this depends on the number of jitter critical communication flows, so it is only possible to implement a few of these buffers in the bridge and give the advice to developers of jitter critical services to implement their own play-out buffer. This should actually be considered as state of the art since it is also needed for transmission over wireless LANs or the internet. 


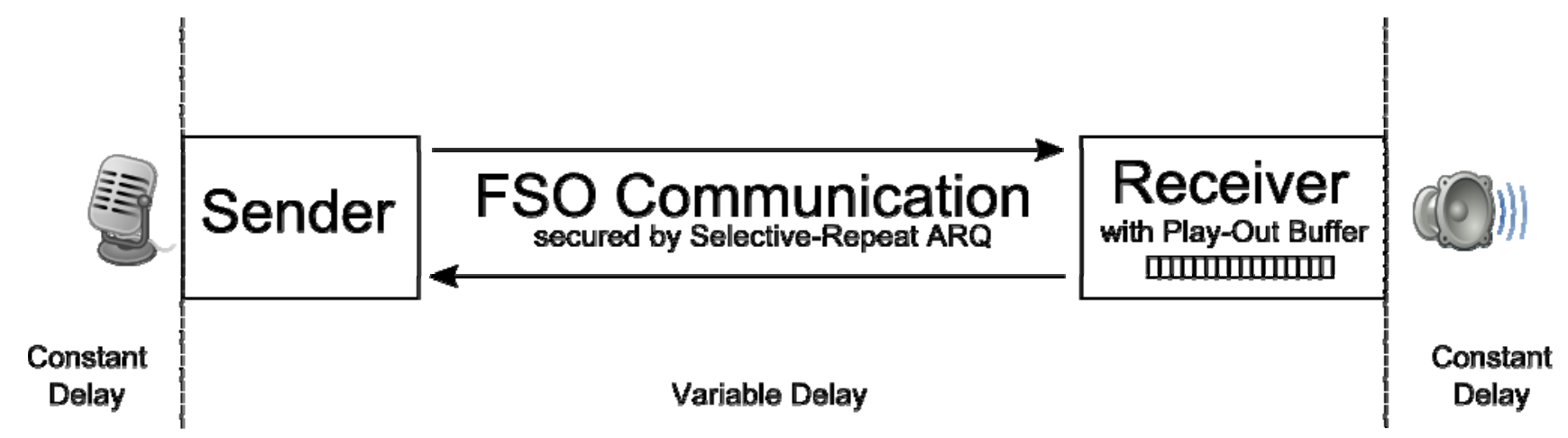

Fig. 3: Play-out buffer concept for removing variable delay introduced by ARQ protocol into the data flow.

If additional buffers are needed at the receiver depends on the ARQ scheme. For Stop-and-Wait ARQ as well as for GoBack-N ARQ no additional buffer is needed as the correctly received packets can be directly put into the play-out buffer. If Selective-Repeat ARQ is implemented an additional buffer is needed. The purpose of this buffer is to reorder the received packets as no reordering of packets should occur on layer 2 and this might happen within Selective-Repeat. The size of this buffer depends on the number of allowed retransmissions. It should be sized at least in the order of the product of the number of retransmissions $N_{\max }$, the round trip time $R T T$ and the data rate $d$.

$$
\text { BufferSize }_{R x}=N_{\max } \times R T T \times d
$$

Assuming again a $1.5 \mathrm{Gbit} / \mathrm{s}$ optical link and a limit of 4 retransmissions the minimum buffer size in the GEO relay scenario would be around 200 Megabyte. For an aircraft to aircraft link it would only be 2 Megabyte. If the buffer size is limited to some smaller value the available buffer space has to be reported to the sender during communication as it is done for example in the Transmission Control Protocol (TCP) of the internet.

\subsection{Filtering Traffic}

For identifying data flows and mapping these into the QoS classes the traffic of the bridged LANs has to be filtered. The filtering of the traffic can be done on many parts of the transported frames. First the traffic can be filtered by the source and destination address of the data. For example if the address of a VoIP phone is known it can be assumed that all traffic going to and coming from this address needs a high priority. Second if IP packets are encapsulated within the Ethernet frames their destination port can be used as identifier of the service, since most services use fixed port numbers on which they are operating. Third the type field of Ethernet frames can be used to identify the frame type. If the frame is marked as VLAN-tagged ${ }^{9}$, the priority can be read directly from this frame. More possibilities to filter traffic on layer 2 and implementation advices are given in ${ }^{3,9}$.

\subsection{Implementation Concept for the FSO Bridge}

The implementation concept for the FSO Bridge presented here is based on the reuse of existing hardware at the DLR. It is illustrated in Figure 3. 


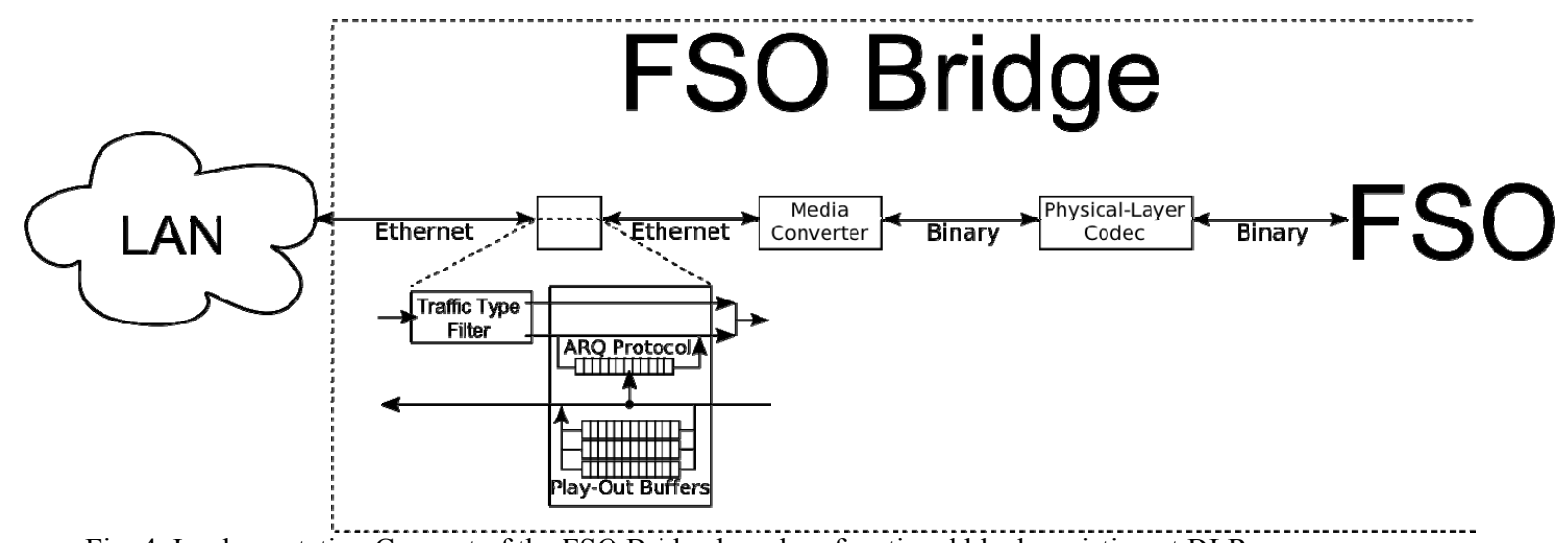

Fig. 4: Implementation Concept of the FSO Bridge based on functional blocks existing at DLR.

It can be seen that the ARQ protocol is implemented on an additional box within the data path. This design allows for the reuse of already existing functional blocks and it also allows removing the additional protocol for scenarios where additional error correction is not needed. It is also possible to replace the protocol by any other type of error correction that might be desired. Existing hardware at DLR is laid out to operate on Fast Ethernet (100 Mbit/s) although it would be possible to implement it the same way for Gigabit Ethernet or higher data rates.

\section{CONCLUSION}

It has been shown that in most FSO communication scenarios it is possible to fulfill the QoS requirements set up by the ITU and the 3GPP. So FSO is a suitable technology for transporting typical multimedia data flows. The main steps that are needed for implementing a device for bridging multimedia data between two LAN have been named and an implementation concept for such a device has been shown. The suggested implementation is based on already developed hardware so the development of the new hardware is limited to the implementation of an additional error correction method within the data path.

${ }^{1}$ European Community $6^{\text {th }}$ Framework Program, MINERVAA, Mid-term Networking Technologies In-Flight and Rig Validation for Avionic Applications.

${ }^{2}$ ETSI 3rd Generation Partnership Project (3GPP), Universal Mobile Telecommunications System (UMTS); Services and service capabilities (3GPP TS 22.105 version 7.1.0 Release 7), European Telecommunications Standards Institute, 2006.

3 IEEE Computer Society, 802.1D IEEE Standard for Local and metropolitan area networks - Media Access Control (MAC) Bridges, The Institute of Electrical and Electronics Engineers, 2004.

${ }^{4}$ V. Jacobson, et al., RFC 2598 An Expedited Forwarding PHB, http://www.ietf.org/rfc/rfc2598.txt, 1999.

5 J. Heinanen, et al., RFC 2597 Assured Forwarding PHB Group, http://www.ietf.org/rfc/rfc2597.txt, 1999.

${ }^{6}$ ITU-T, G.1010 Series G: Transmission Systems and Media, Digital Systems and Networks - Quality of service and performance End-user multimedia QoS categories, International Telecommunication Union, 2001.

${ }^{7}$ H. Henniger, Multi Layer Error Protection on Simplex Links, to be published in Proceedings of the SPIE, Vol. 6877 , 2008.

${ }^{8}$ B. Epple, Performance Optimization of Free-Space Optical Communication Protocols based on results from FSO Demonstrations, Proceedings of the SPIE, Vol. 6709, 2007.

${ }^{9}$ IEEE Computer Society, 802.1Q IEEE Standard for Local and metropolitan area networks - Virtual Bridged Local Area Networks, The Institute of Electrical and Electronics Engineers, 2006. 